\title{
High Cysteine Diet Reduces Insulin Resistance in SHR-CRP Rats
}

\author{
Jakub KRIJT ${ }^{1}$, Jitka SOKOLOVÁ ${ }^{1}$, Jan ŠILHAVÝ ${ }^{2}$, Petr MLEJNEK ${ }^{2}$, Jan KUBOVČIAK ${ }^{3}$, \\ František LIŠKA ${ }^{2,4}$, Hana MALÍNSKÁ ${ }^{5}$, Martina HÜTTL ${ }^{5}$, Irena MARKOVÁ ${ }^{5}$, Michaela \\ KŘÍŽKOVÁ ${ }^{1}$, Martha H. STIPANUK ${ }^{6}$, Tomáš KŘÍŽEK ${ }^{7}$, Tamas DITROI ${ }^{8}$, Peter NAGY ${ }^{8,9}$, \\ Viktor KOŽICH ${ }^{1}$, Michal PRAVENEC ${ }^{2,4}$
}

${ }^{1}$ Department of Pediatrics and Inherited Metabolic Disorders, Charles University-First Faculty of Medicine and General University Hospital in Prague, Prague, Czech Republic, ${ }^{2}$ Laboratory of Genetics of Model Diseases, Institute of Physiology of the Czech Academy of Sciences, Prague, Czech Republic, ${ }^{3}$ Laboratory of Genomics and Bioinformatics, Institute of Molecular Genetics of the Czech Academy of Sciences, Prague, Czech Republic, ${ }^{4}$ Institute of Biology and Medical Genetics, First Faculty of Medicine, Charles University and General University Hospital, Prague, Czech Republic, ${ }^{5}$ Centre for Experimental Medicine, Institute for Clinical and Experimental Medicine, Prague, Czech Republic, ${ }^{6}$ Division of Nutritional Sciences, Cornell University, Ithaca, NY, USA, ${ }^{7}$ Department of Analytical Chemistry, Faculty of Science, Charles University, Prague, Czech Republic, ${ }^{8}$ Department of Molecular Immunology and Toxicology, National Institute of Oncology, Budapest, Hungary, ${ }^{9}$ Department of Anatomy and Histology, University of Veterinary Medicine, Budapest, Hungary

Received May 28, 2021

Accepted June 18, 2021

Epub Ahead of Print September 10, 2021

\section{Summary}

Increased plasma total cysteine (tCys) has been associated with obesity and metabolic syndrome in human and some animal studies but the underlying mechanisms remain unclear. In this study, we aimed at evaluating the effects of high cysteine diet administered to SHR-CRP transgenic rats, a model of metabolic syndrome and inflammation. SHR-CRP rats were fed either standard (3.2 g cystine/ $\mathrm{kg}$ diet) or high cysteine diet (HCD, enriched with additional $4 \mathrm{~g} \mathrm{L-cysteine/kg} \mathrm{diet).} \mathrm{After} 4$ weeks, urine, plasma and tissue samples were collected and parameters of metabolic syndrome, sulfur metabolites and hepatic gene expression were evaluated. Rats on HCD exhibited similar body weights and weights of fat depots, reduced levels of serum insulin, and reduced oxidative stress in the liver. The HCD did not change concentrations of tCys in tissues and body fluids while taurine in tissues and body fluids, and urinary sulfate were significantly increased. In contrast, betaine levels were significantly reduced possibly compensating for taurine elevation. In summary, increased Cys intake did not induce obesity while it ameliorated insulin resistance in the SHR-CRP rats, possibly due to beneficial effects of accumulating taurine.

\section{Key words}

SHR-CRP rats - Metabolic syndrome - Taurine • Cysteine • Insulin resistance $\bullet$ Cysteine dioxygenase

\section{Corresponding authors}

M. Pravenec, Laboratory of Genetics of Model Diseases, Institute of Physiology of the Czech Academy of Sciences, Vídeňská 1083, 14220 Praha 4, Czech Republic. E-mail: michal.pravenec@fgu.cas.cz and V. Kožich, Department of Pediatrics and Inherited Metabolic Disorders, Charles University-First Faculty of Medicine and General University Hospital in Prague, Ke Karlovu 2, 12808 Praha 2, Czech Republic. E-mail: viktor.kozich@vfn.cz

\section{Introduction}

Cysteine (Cys) is a conditionally essential and potentially obesogenic amino acid which can be obtained from the diet, breakdown of body proteins or synthesized endogenously from methionine (Met) by a sequence of transmethylation and transsulfuration reactions (Olsen

PHYSIOLOGICAL RESEARCH • ISSN 1802-9973 (online) - an open access article under the CC BY-NC-ND 4.0 license (c) 2021 Institute of Physiology of the Czech Academy of Sciences, Prague, Czech Republic 
et al. 2018, Brosnan and Brosnan 2006). Cys is the ratelimiting substrate for synthesis of the major intracellular antioxidant glutathione (GSH) and its availability is also essential for synthesis of proteins, coenzyme A, hydrogen sulfide $\left(\mathrm{H}_{2} \mathrm{~S}\right)$ and taurine (Tau). Cys is tightly regulated to maintain its steady-state concentrations below the threshold of cytotoxicity (Stipanuk et al. 2006, Stipanuk 2020). Cys is catabolized via CDO-dependent pathway or via several desulfhydration reactions. The main CDO-dependent catabolic pathway converts Cys to cysteinesulfinate with subsequent channeling into either the decarboxylation route yielding Tau or the transamination pathway that produces inorganic sulfite and sulfate. To a lesser extent Cys is catabolized to $\mathrm{H}_{2} \mathrm{~S}$ by the cytosolic desulfhydration pathways involving cystathionine beta-synthase, gamma-cystathionase and aspartate aminotransferase with mercaptopyruvate sulfurtransferase. Hydrogen sulfide is subsequently converted by a series of enzymatic reactions located in mitochondria to glutathione persulfide, sulfite, or thiosulfate and sulfate (Fig. 1).

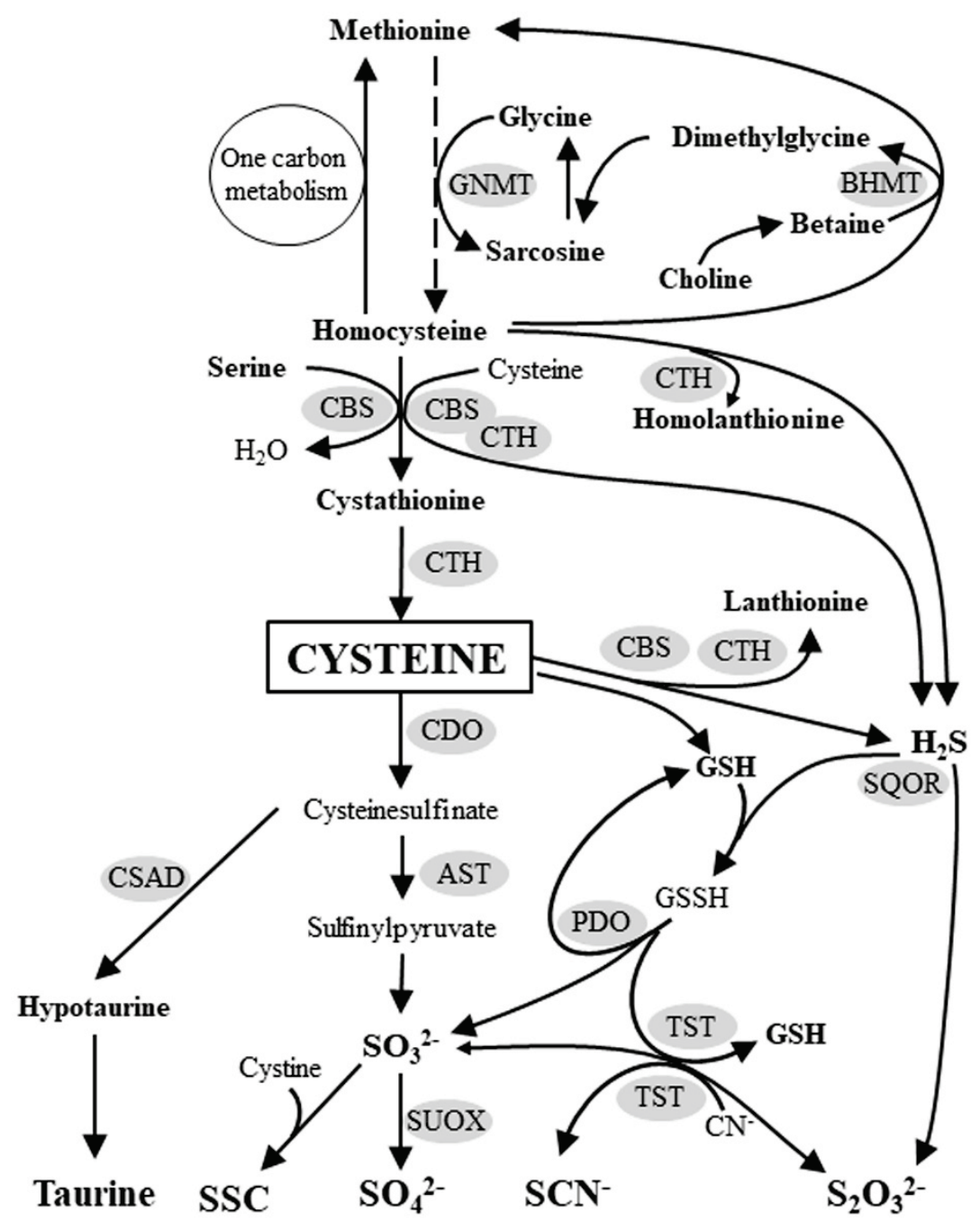

Fig. 1. Cysteine synthesis and catabolism. Cys is produced by transsulfuration pathway from dietary Met and is catabolized either by decarboxylation pathway (end-product taurine), transamination pathway (end-product sulfate) or desulfhydration pathways (product hydrogen sulfide). Hydrogen sulfide is converted by enzymatic reactions located in mitochondria to sulfite, thiosulfate and sulfate. Abbreviations: CBS, cystathionine beta-synthase; CSAD, cysteine sulfinic acid decarboxylase; AST, aspartate aminotransferase; CDO, cysteine dioxygenase; CTH, gamma-cystathionase; GSH, glutathione; GSSH, glutathione persulfide; GNMT, glycine N-methyltransferase; BHMT, betaine:homocysteine methyltransferase; $\mathrm{H}_{2} \mathrm{~S}$, hydrogen sulfide; PDO, persulfide dioxygenase; SUOX, sulfite oxidase; SQOR, sulfide:quinonenoxidoreductase; TST, thiosulfate transferase; $\mathrm{SO}_{3}{ }^{2-}$, sulfite; $\mathrm{SO}_{4}{ }^{2-}$, sulfate; $\mathrm{S}_{2} \mathrm{O}_{3}{ }^{2-}$, thiosulfate; $\mathrm{SCN}^{-}$, thiocyanate; SSC, S-sulfocysteine.

A strong direct association between plasma total cysteine (tCys, i.e. the sum of reduced, oxidized and protein bound cysteine) and components of metabolic syndrome such as obesity, BMI, fat mass, insulin resistance, central adiposity and lipid metabolism has been shown in previous studies involving human subjects (Elshorbagy et al. 2012c, Elshorbagy et al. 2012b, El-Khairy et al. 1999, Elshorbagy et al. 2008). Moreover, intermediate phenotypes (e.g. activity of the lipogenic enzyme stearoyl-CoA desaturase, fibroblast growth factor 21, IGF-1, serum leptin and triglycerides) are adversely influenced by high-cysteine (HCD) and/or high methionine diet and reversed by sulfur amino acid restriction (Elshorbagy et al. 2012d, Olsen et al. 2020, Niewiadomski et al. 2016, Olsen et al. 2018, Elshorbagy et al. 2012a). All these findings strongly support the 
hypothesis that Cys is causally related to obesity and pathogenesis of metabolic syndrome in humans. In contrast, several studies in rodents indicated beneficial effect of increased Cys intake on metabolic syndrome components. Treatment of Zucker diabetic fatty rats with Cys supplemented diet reduced glycemia, lowered insulin resistance, reduced oxidative stress and decreased levels of inflammatory markers (Jain et al. 2009). Similarly, increased Cys intake prevented oxidative stress and development of insulin resistance after feeding rats with high-sucrose diet (Blouet et al. 2007). Controversies on the effects of $\mathrm{HCD}$ or Cys restricted diet on the components of metabolic syndrome in humans and rodent models raise a question whether the elevated levels of Cys found in obese patients result from excessive dietary intake, increased endogenous Cys production or decreased catabolism. In this study, we hypothesized that high Cys intake would increase adiposity and insulin resistance in a rodent model of metabolic syndrome and inflammation (SHR-CRP strain), and we explored the metabolic and molecular consequences of this dietary intervention.

\section{Methods}

\section{Study design}

As obesity is associated with chronic inflammation, we studied obesogenic effects of HCD in SHR-CRP strain, a model of metabolic syndrome and inflammation. The experiment was conducted in 3-month-old male SHR-CRP transgenic rats expressing the human CRP gene under control of the apolipoprotein E promoter with the objective of driving expression of the CRP transgene in liver where CRP is normally produced (Pravenec et al. 2011). In the current study, we tested the hypothesis that feeding HCD is associated with increased adiposity and insulin resistance as primary outcomes. A total of 16 SHR-CRP rats were divided into two groups and fed with different experimental diets for 4 weeks. The first group was fed standard diet (SD) Altromin 1314 (3.244 g cystine $/ \mathrm{kg}$ diet, $3.171 \mathrm{~g} \mathrm{Met} / \mathrm{kg}$ diet). The second group received HCD, consisting of Altromin 1314 enriched with $4 \mathrm{~g}$ L-cysteine/ $\mathrm{kg}$ diet. The estimated daily intake of Cys, calculated on the expected $28 \mathrm{~g}$ daily intake of the diet, was approximately 1.7 and 0.75 mmoles in the HCD and SD fed rats, respectively. The daily Met intake in both diets was 0.6 mmoles. After 4 weeks of dietary treatment, urine was collected, rats were sacrificed by decapitation, and blood and tissues (liver, kidney, brain, muscle) were collected. Urine was collected only from 12 animals - 6 urine samples from each group. The urine was collected in metabolic cages overnight for $16 \mathrm{~h}$. All experiments were performed in agreement with the Animal Protection Law of the Czech Republic and approved by the Ethics Committee of the Institute of Physiology, Czech Academy of Sciences, Prague, Czech Republic (71/2015).

\section{Determination of metabolic syndrome parameters}

Basal and insulin-stimulated glucose utilisation

in isolated epididymal adipose tissue and muscles. For measurement of insulin-stimulated incorporation of glucose into lipids or glycogen, epididymal adipose tissue or diaphramatic muscle was incubated for $2 \mathrm{~h}$ in $95 \% \mathrm{O}_{2}$ $+5 \% \mathrm{CO}_{2}$ in Krebs-Ringer bicarbonate buffer ( $\mathrm{pH} 7.4$ ) containing $0.1 \mu \mathrm{Ci} / \mathrm{ml}$ of ${ }^{14} \mathrm{C}-\mathrm{U}$ glucose, $5 \mathrm{mmol} / \mathrm{l}$ of unlabelled glucose and $2.5 \mathrm{mg} / \mathrm{ml}$ of bovine serum albumin (Fraction V, Sigma, Czech Republic) with and without $250 \mu \mathrm{U} / \mathrm{ml}$ of insulin. Extraction of lipids or glycogen was followed by a determination of insulinstimulated incorporation of glucose into lipids or glycogen (Malinska et al. 2015).

Tissue triglyceride measurements. For determination of triglycerides in liver, gastrocnemius muscle and heart, tissues were powdered under liquid $\mathrm{N}_{2}$ and extracted for $16 \mathrm{~h}$ in chloroform:methanol, after which $2 \% \mathrm{KH}_{2} \mathrm{PO}_{4}$ was added and the solution was centrifuged. The organic phase was collected and evaporated under $\mathrm{N}_{2}$. The resulting pellet was dissolved in isopropyl alcohol, and triglyceride concentrations were determined by an enzymatic assay (Erba-Lachema, Brno, Czech Republic).

Biochemical analyses. Blood glucose levels were measured by the glucose oxidase assay (Erba Lachema, Brno, Czech Republic) using tail vein blood drawn into $5 \%$ trichloroacetic acid and promptly centrifuged. Non-esterified fatty acids levels were determined using an acyl-CoA oxidase-based colorimetric kit (Roche Diagnostics GmbH, Mannheim, Germany). Serum triglyceride concentrations were measured by standard enzymatic methods (Erba Lachema, Brno, Czech Republic). Serum insulin and leptin concentrations were determined using a rat insulin ELISA kit (Mercodia, Uppsala, Sweden; MyBioSource, USA).

Parameters of oxidative stress. Oxidative stress was measured according to the activities of antioxidant enzymes, concentrations of reduced and oxidized 
glutathione, and levels of lipoperoxidation products thiobarbituric acid-reactive substances (TBARS) (Malinska et al. 2015). The activity of superoxide dismutase (SOD), glutathione peroxidase (GSH-Px) and glutathione reductase (GR) were analyzed using Cayman Chemicals assay kits (MI, USA). Catalase (CAT) activity measurement was based on the ability of $\mathrm{H}_{2} \mathrm{O}_{2}$ and ammonium molybdate to produce a colour complex that was detected spectrophotometrically. Lipoperoxidation products were assessed according to concentrations of TBARS determined by assaying the reaction with thiobarbituric acid. The levels of conjugated dienes were analyzed by extraction from the media into heptane:isopropanol $(2: 1)$ and measured spectrophotometrically in the heptane layer. Concentrations of reduced (GSH) and oxidised (GSSG) forms of glutathione were determined using a HPLC diagnostic kit with fluorescence detection (ChromSystems, Germany).

\section{Metabolite analyses}

Tissue sample preparation: Tissue samples were weighed and homogenized mechanically using Tissue raptor homogenizer (Qiagen) in buffer containing $1.5 \%$ of laurylmaltoside in $100 \mathrm{mM}$ Tris, $\mathrm{pH} 8.5$ while tubes were held in an ice/water slush. For every $10 \mathrm{mg}$ of tissue we used $60 \mu \mathrm{l}$ of buffer. Tissue homogenates were centrifuged at $4{ }^{\circ} \mathrm{C}$ at $15,000 \times \mathrm{g}$ for $20 \mathrm{~min}$. The supernatant was aliquoted and stored at $-80{ }^{\circ} \mathrm{C}$ prior to metabolite analyses.

LC-MS/MS methods: Previously published LC-MS/MS method was used for determination of Tau, hypotaurine, choline, betaine, dimethylglycine and S-sulfocysteine (Kozich et al. 2019). Commercially available kit was used for LC-MS/MS determination of amino acids Met, lanthionine and sarcosine (EZ:faast, Phenomenex, Torrance, USA). All LC-MS/MS analyses were performed on a system consisting of the Agilent 1290 Infinity LC System (Agilent Technologies, Palo Alto, CA, USA) coupled with an API 4000 triple quadrupole mass spectrometer with an electrospray ion source. Detection of analytes was carried out using positive electrospray ionization technique and selected multiple reaction monitoring.

HPLC and capillary electrophoresis methods: Total aminothiols (Cys, cysteinyl-glycine, homocysteine, glutathione and $\gamma$-glutamyl-cysteine) and inorganic sulfur compounds (sulfite, thiosulfate, thiocyanate and hydrogen sulfide) were determined by reversed-phase HPLC with fluorescent detection (Shimadzu LC-20AD system with RF-20AXs fluorescence detector, Shimadzu Corporation,
Kyoto, Japan). Aminothiols were derivatized with ammonium 7-fluorobenzo-2-oxa-1,3-diazole-4-sulfonate (SBD-F) after the reduction of disulphide bonds with tris(2-carboxyethyl)phosphine (TCEP) as described previously (Krijt et al. 2001). Sulfite, thiosulfate and thiocyanate were analyzed after derivatization with monobromobimane as described previously (Kozich et al. 2019), bioavailable hydrogen sulfide measurements were carried out as described before in (Ditroi et al. 2019). Sulfate was determined by Agilent 7100 capillary electrophoresis system (Agilent Technologies, Waldbronn, Germany) equipped with a capacitively coupled contactless conductivity detection: $50 \mu \mathrm{l}$ of plasma sample was mixed with $5 \mu \mathrm{l}$ of $10 \mathrm{mM}$ potassium chlorate and $145 \mu \mathrm{l}$ of acetonitrile while for urinary analysis $5 \mu \mathrm{l}$ of urine was mixed with $50 \mu \mathrm{l}$ of water, $5 \mu \mathrm{l}$ of $10 \mathrm{mM}$ potassium chlorate and $140 \mu \mathrm{l}$ of acetonitrile. The resulting mixtures were centrifuged at $14,500 \times \mathrm{g}$ for $10 \mathrm{~min}$ and supernatant was injected into the unmodified fused-silica capillary $(50 \mu \mathrm{m}$ ID and $375 \mu \mathrm{m}$ OD; Polymicro Technologies, Phoenix, AZ, USA). Between individual runs the capillary was flushed for 2 min with $1 \mathrm{M} \mathrm{NaOH}$, 1 min with water and 2 min with background electrolyte. Background electrolyte consisted of $1 \mathrm{M}$ formic acid in water. Samples were injected using a pressure of $5 \mathrm{kPa}$ for $5 \mathrm{~s}$. A voltage of $-25 \mathrm{kV}$ was applied during the analysis. Conductivity detector provided positive signal for sulfate and chlorate (internal standard). Concentration of sulfate was calculated from the ratio of sulfate and chlorate peak areas. Calibration curves were constructed using standard solutions in water for analysis of urine and plasma spiked with sulfate standard solutions for analysis of plasma.

Assessment of renal handling of metabolites. The fractional excretion (excretional fraction, EF) of metabolites was calculated using the standard formula: $\mathrm{EF}_{\text {metabolite }}[\%]=100 \times\left(\mathrm{U}_{\text {metabolite }} \times \mathrm{P}_{\text {creatinine }}\right) /\left(\mathrm{P}_{\text {metabolite }} \times\right.$ $\left.\mathrm{U}_{\text {creatinine}}\right)$, where $\mathrm{U}$ and $\mathrm{P}$ are concentrations of analytes determined in simultaneously obtained urine and plasma samples, respectively. Creatinine in urine and plasma was determined using the automated analyzer Hitachi 902 and the commercially available kit "Creatinine" (Jaffe method, Erba Lachema, Czech Republic) and "Creatinine enzymatic" (Erba Lachema, Czech Republic), respectively.

\section{Gene expression profiling and $q P C R$ studies}

$R N A$ isolation: Livers were homogenized in Trizol (ThermoFisher) using TissueLyser LT (Qiagen) at $50 \mathrm{~Hz}$ for $5 \mathrm{~min}$. Chloroform was then used for phase separation, and the aqueous phase was mixed 1:1 with 
$70 \%$ ethanol, applied to RNeasy mini spin columns and purified using RNeasy Plus Mini Kit (Qiagen) according to manufacturer's protocol. RNA was quantified by spectrophotometry.

RNAseq method: We used RNAseq method for determination of gene expression profiles as described (Lunova et al. 2021). Library preparation was done with SENSE total RNA AEQ library prep kit for Illumina (Lexogene, PN A01107). Library size distribution was evaluated on the Agilent 2100 Bioanalyzer using the High Sensitivity DNA Kit (Agilent). Libraries were sequenced on the Illumina NextSeq ${ }^{\circledR} 500$ instrument using $84 \mathrm{bp}$ single-end configuration. Read quality was assessed by FastQC. For subsequent read processing, a bioinformatic pipeline nf-core/rnaseq version 1.4.2, was used. Individual steps included removing sequencing adaptors with Trim Galore, mapping to reference genome Rnor_6.0 (Ensembl annotation version 99) with HISAT2 and quantifying expression on gene level with featureCounts. Per gene mapped counts served as input for differential expression analysis using DESeq2 R Bioconductor package. Prior to the analysis, genes not expressed in at least two samples were discarded. Shrunken log2-fold changes using the adaptive shrinkage estimator were used for differential expression analysis. We supplied experimental model assuming sample treatment as main effect. Genes exhibiting minimal absolute $\log _{2}$-fold change value of 1 and statistical significance (adjusted p-value $<0.05$ ) between compared groups of samples were considered as differentially expressed. Gene set enrichment analysis was done using gene length bias aware algorithm implemented in goseq $\mathrm{R}$ Bioconductor package with KEGG pathways and GO terms data.

Quantitative PCR ( $q P C R$ ). $1 \mu \mathrm{g}$ total RNA was used to synthesize cDNA using SuperScript IV reverse transcriptase (ThermoFisher) according to manufacturer's protocol. The resulting cDNAs were then used as templates in quantitative real-time PCR (qPCR) reactions. Primers for qPCR reactions (Table S1) were designed using PrimerBLAST (Ye et al. 2012) to span at least one exonexon junction: amplicon size was set to 70-150 bp. Each qPCR reaction contained equivalent of $8 \mathrm{ng}$ of input RNA, $300 \mathrm{nM}$ of each forward and reverse primer and $1 \times$ Power-up SYBRGreen master mix (Thermofisher) and was amplified in 7900HT (Applied Biosystems).

For qPCR experiment, cycle threshold $(\mathrm{Ct})$ values of selected genes were normalized relative to the expression of peptidylprolyl isomerase A (Ppia, cyclophilin) gene (for liver), which served as the internal control, with results being determined in triplicates. Relative quantification was performed using the $\Delta \Delta \mathrm{Ct}$ method.

\section{Statistical analyses}

The data presented in tables are shown as mean and standard deviation. Outlying values were excluded using Grubbs test. Parametric $t$-test with BenjaminiHochberg correction for multiple testing was used for comparison of the HCD and SD groups, significance of the false discovery rate (FDR) was set at $<0.05$. All statistical analyses were performed using Statistica $\mathrm{Cz}$, version 14 (StatSoft, Inc., USA).

\section{Results}

Effects of HCD on glucose and lipid metabolism and parameters of oxidative stress and inflammation

Compared to controls on SD the SHR-CRP rats fed a HCD had similar body weight, weight of epididymal and perirenal fat depots, and serum triglyceride levels but exhibited increased serum NEFA concentrations (Table 1). HCD reduced significantly levels of serum insulin. Serum glucose tended to be lower but the difference did not achieve statistical significance. Insulin stimulated adipogenesis in white adipose tissue tended to be increased after HCD but the difference was also not statistically significant. Together these results suggest amelioration of insulin resistance in rats fed HCD. In addition, feeding of HCD reduced oxidative stress as evidenced by significantly lower hepatic concentrations of lipoperoxidation products TBARS and increased activity of GSH peroxidase (Table 2). There were no significant effects of HCD on serum markers of inflammation as MCP-1, IL6, and TNF- $\alpha$ concentrations were similar to controls on SD (data not shown).

\section{Effects of HCD on metabolite profiles}

\section{Concentration of Cys in tissues and body fluids}

The levels of tCys and related analytes in body fluids and tissue samples from rats on HCD and SD are summarized in Tables 3-4; relative changes in animals fed HCD compared to SD are shown in Table S2. In accordance with previous studies (Stipanuk et al. 2009, Stipanuk and Ueki 2011) the HCD did not elicit any significant elevation of tCys in tissues, plasma or urine, demonstrating the tight regulation of Cys homeostasis. 
Table 1. Body and organ weights and parameters of glucose and lipid metabolism in SHR-CRP transgenic rats treated with high cysteine diet (HCD) or standard diet (SD).

\begin{tabular}{|c|c|c|}
\hline & SD & HCD \\
\hline Body weight (g) & $392 \pm 12$ & $390 \pm 18$ \\
\hline Weight of epididymal fat ( $g$ ) & $2.55 \pm 0.32$ & $2.27 \pm 0.82$ \\
\hline Weight of perirenal fat $(\mathrm{g})$ & $2.09 \pm 0.38$ & $2.16 \pm 0.41$ \\
\hline Liver weight $(g)$ & $13.3 \pm 0.5$ & $12.7 \pm 0.9$ \\
\hline Serum glucose (mmol/l) & $8.09 \pm 0.31$ & $7.67 \pm 0.33$ \\
\hline Serum insulin (nmol/l) & $0.55 \pm 0.18$ & $0.31 \pm 0.10 *$ \\
\hline Serum triglycerides (mmol/l) & $0.56 \pm 0.10$ & $0.56 \pm 0.11$ \\
\hline Serum NEFA (mmol/l) & $0.50 \pm 0.05$ & $0.62 \pm 0.10^{*}$ \\
\hline Serum cholesterol (mmol/l) & $1.33 \pm 0.14$ & $1.35 \pm 0.22$ \\
\hline Serum HDL cholesterol (mmol/l) & $1.23 \pm 0.14$ & $1.29 \pm 0.19$ \\
\hline Liver triglycerides $(\mu \mathrm{mol} / \mathrm{g})$ & $8.85 \pm 2.47$ & $8.67 \pm 1.31$ \\
\hline Muscle gastrocnemius triglycerides ( $\mu$ mol/g) & $2.23 \pm 0.97$ & $3.75 \pm 2.83$ \\
\hline Heart triglycerides $(\mu \mathrm{mol} / \mathrm{g})$ & $1.49 \pm 0.24$ & $0.88 \pm 0.14^{*}$ \\
\hline $\begin{array}{l}\text { Sensitivity of white adipose tissue to insulin action (nmol } \\
\text { glucose incorporated/g tissue/2 h) }\end{array}$ & $482 \pm 85$ & $782 \pm 482$ \\
\hline
\end{tabular}

$t$-test with Benjamini-Hochberg correction; * bold, significant difference with FDR $<0.05$.

Table 2. Parameters of oxidative stress in the liver in SHR-CRP transgenic rats treated with high cysteine diet (HCD) or control diet (SD).

\begin{tabular}{|c|c|c|}
\hline & SD & HCD \\
\hline$S O D(U / m g)$ & $0.13 \pm 0.02$ & $0.14 \pm 0.03$ \\
\hline GSH-Px ( $\mu M N A D P H / \mathrm{min} / \mathrm{mg})$ & $270 \pm 65$ & $354 \pm 46 *$ \\
\hline GR ( $\mu M$ NADPH/min/mg) & $122 \pm 23$ & $133 \pm 30$ \\
\hline $\mathrm{CAT}\left(\mathrm{mM} \mathrm{H} \mathrm{H}_{2} \mathrm{O}_{2} / \mathrm{min} / \mathrm{mg}\right)$ & $1539 \pm 355$ & $1704 \pm 422$ \\
\hline GSH ( $\mu \mathrm{mol} / \mathrm{mg}$ protein) & $56.0 \pm 2.2$ & $53.6 \pm 2.4$ \\
\hline GSSG ( $\mu \mathrm{mol} / \mathrm{mg}$ protein) & $2.16 \pm 0.04$ & $1.69 \pm 0.21$ \\
\hline$G S H / G S S G$ & $27.0 \pm 5.4$ & $29.9 \pm 7.4$ \\
\hline Conjugated dienes (nM/mg) & $28.4 \pm 3.9$ & $24.3 \pm 4.1$ \\
\hline$T B A R S(n M / m g)$ & $1.78 \pm 0.48$ & $1.17 \pm 0.16 *$ \\
\hline
\end{tabular}

$t$-test with Benjamini-Hochberg correction; * bold, significant difference with FDR $<0.05$.

\section{Indices of Cys catabolism}

\section{Metabolites of the decarboxylation pathway}

The end product of the catabolic decarboxylation pathway Tau was significantly increased to $\approx 1.2-4.5$-fold in urine and tissues except the brain and increased to $\approx 3$-fold in the EF of HCD-fed animals. Concentration of the intermediate hypotaurine was also increased to $\approx 2$-fold in urine obtained from rats on HCD.

Metabolites of the cysteine transamination and desulfhydration pathways

Sulfite is produced as an intermediate in the transamination of cysteinesulfinate and the desulfhydration pathways, and its levels in tissues, plasma and urine were not significantly different between rats fed HCD and SD. However, excretion of more stable markers of sulfite accumulation, i.e. S-sulfocysteine, thiosulfate and thiocyanate, was increased to $\approx 1.3-1.5$-fold. Hydrogen sulfide originating from the desulfhydration pathway was elevated to $\approx 2.3$-fold in plasma of HCD fed animals while the byproduct of $\mathrm{H}_{2} \mathrm{~S}$ synthesis - lanthionine - was significantly elevated only in the muscle. Finally, urinary excretion of the final product of sulfite oxidation - sulfate - was significantly increased to $\approx 1$.6-fold by HCD. 
Table 3. Concentrations of cysteine and related metabolites in tissues of rats on HCD and SD.

\begin{tabular}{|c|c|c|c|c|c|c|c|c|}
\hline & \multicolumn{8}{|c|}{ Concentrations in tissues ( $\mu \mathrm{mol} / g$ protein* (except for ratios)) } \\
\hline & \multicolumn{2}{|c|}{ Liver } & \multicolumn{2}{|c|}{ Kidney } & \multicolumn{2}{|c|}{ Brain } & \multicolumn{2}{|c|}{ Muscle } \\
\hline & SD & HCD & SD & HCD & SD & HCD & SD & HCD \\
\hline Total cysteine & $4.97 \pm 2.20$ & $4.58 \pm 1.49$ & $23.7 \pm 3.4$ & $23.1 \pm 1.6$ & $11.8 \pm 0.6$ & $10.6 \pm 1.4$ & $2.93 \pm 2.03$ & $1.82 \pm 0.58$ \\
\hline \multicolumn{9}{|c|}{ Cysteine catabolism - decarboxylation pathway } \\
\hline Hypotaurine & $2.58 \pm 1.07$ & $2.65 \pm 1.09$ & $2.38 \pm 0.55$ & $2.62 \pm 0.69$ & $0.95 \pm 0.10^{*}$ & $1.07 \pm 0.10 *$ & $4.50 \pm 1.16$ & $6.54 \pm 2.45$ \\
\hline Taurine (Tau) & $20.0 \pm 14.1$ & $90.4 \pm 15.5^{*}$ & $77.3 \pm 5.2$ & $95.0 \pm 12.0^{*}$ & $60.5 \pm 7.2$ & $49.8 \pm 8.2^{*}$ & $358 \pm 67$ & $536 \pm 156^{*}$ \\
\hline \multicolumn{9}{|c|}{ Cysteine catabolism - transamination pathway } \\
\hline Sulfite & $0.034 \pm 0.006$ & $0.036 \pm 0.004$ & $0.0018 \pm 0.0002$ & $0.0019 \pm 0.0002$ & $0.0022 \pm 0.0002$ & $0.0022 \pm 0.0003$ & $0.013 \pm 0.006$ & $0.016 \pm 0.006$ \\
\hline \multicolumn{9}{|c|}{ Cysteine catabolism - desulfhydration and related analytes } \\
\hline $\begin{array}{l}\text { Hydrogen } \\
\text { sulfide }\end{array}$ & $0.0068 \pm 0.0017$ & $0.0078 \pm 0.0017$ & $0.012 \pm 0.002$ & $0.014 \pm 0.002$ & NA & NA & NA & NA \\
\hline Thiosulfate & $0.013 \pm 0.003$ & $0.012 \pm 0.002$ & $0.18 \pm 0.03$ & $0.17 \pm 0.02$ & $0.016 \pm 0.003$ & $0.013 \pm 0.003$ & $0.038 \pm 0.012$ & $0.038 \pm 0.012$ \\
\hline Thiocyanate & $0.18 \pm 0.09$ & $0.15 \pm 0.06$ & $1.02 \pm 0.20$ & $0.95 \pm 0.34$ & $0.32 \pm 0.0$ & $0.27 \pm 0.04 *$ & $0.60 \pm 0.14$ & $0.77 \pm 0.23$ \\
\hline S-sulfocysteine & ND & ND & ND & ND & ND & ND & ND & ND \\
\hline Lanthionine & ND & ND & $0.0073 \pm 0.0016$ & $0.0069 \pm 0.0012$ & $0.0044 \pm 0.0016$ & $0.0048 \pm 0.0015$ & $0.0045 \pm 0.0017^{*}$ & $0.0072 \pm 0.0024 *$ \\
\hline \multicolumn{9}{|c|}{ Glutathion metabolism } \\
\hline Glutathione & $40.4 \pm 5.5$ & $40.0 \pm 2.4$ & $0.12 \pm 0.01$ & $0.13 \pm 0.01$ & $2.06 \pm 0.47$ & $1.76 \pm 0.60$ & $16.8 \pm 5.9$ & $23.4 \pm 9.2$ \\
\hline $\begin{array}{l}\gamma \text {-Glutamyl- } \\
\text { cysteine }\end{array}$ & $0.055 \pm 0.005$ & $0.068 \pm 0.017$ & $0.27 \pm 0.03$ & $0.29 \pm 0.03$ & $0.17 \pm 0.01$ & $0.18 \pm 0.02$ & $0.0073 \pm 0.0016$ & $0.0071 \pm 0.0018$ \\
\hline Cysteinylglycine & $0.36 \pm 0.04$ & $0.35 \pm 0.02$ & $0.49 \pm 0.06$ & $0.51 \pm 0.06$ & $0.11 \pm 0.02$ & $0.11 \pm 0.02$ & $0.21 \pm 0.12$ & $0.14 \pm 0.04$ \\
\hline \multicolumn{9}{|c|}{ Methionine cycle and related analytes } \\
\hline Methionine & $0.46 \pm 0.07$ & $0.42 \pm 0.06$ & $2.67 \pm 0.48$ & $2.64 \pm 0.45$ & $0.36 \pm 0.06$ & $0.34 \pm 0.04$ & $0.91 \pm 0.24$ & $1.00 \pm 0.39$ \\
\hline $\begin{array}{l}\text { Total } \\
\text { homocysteine }\end{array}$ & $0.11 \pm 0.01$ & $0.11 \pm 0.01$ & $0.28 \pm 0.03$ & $0.27 \pm 0.01$ & $0.063 \pm 0.005$ & $0.053 \pm 0.017$ & $0.012 \pm 0.004$ & $0.014 \pm 0.007$ \\
\hline Met/tHcy & $4.37 \pm 0.62$ & $3.97 \pm 0.64$ & $9.58 \pm 0.92$ & $9.96 \pm 1.75$ & $5.43 \pm 0.46$ & $7.11 \pm 2.30$ & $68.2 \pm 14.7$ & $97.1 \pm 70.8$ \\
\hline Choline & $4.36 \pm 0.53$ & $4.72 \pm 1.58$ & $24.1 \pm 4.5$ & $24.1 \pm 3.1$ & $6.52 \pm 0.32$ & $6.37 \pm 1.10$ & $0.93 \pm 0.13$ & $1.84 \pm 0.54 *$ \\
\hline Betaine & $15.6 \pm 4.1$ & $7.7 \pm 1.1^{*}$ & $18.9 \pm 3.7$ & $13.6 \pm 4.7 *$ & $0.22 \pm 0.04$ & $0.17 \pm 0.05 *$ & $4.36 \pm 1.34$ & $3.63 \pm 1.34$ \\
\hline Dimethylglycine & $0.53 \pm 0.09$ & $0.27 \pm 0.05 *$ & $0.072 \pm 0.018$ & $0.045 \pm 0.007 *$ & $0.0022 \pm 0.0014$ & $0.0012 \pm 0.0008$ & $0.14 \pm 0.04$ & $0.13 \pm 0.05$ \\
\hline Sarcosine & $0.30 \pm 0.08$ & $0.25 \pm 0.06$ & $0.078 \pm 0.009$ & $0.060 \pm 0.009 *$ & $0.0068 \pm 0.0017$ & $0.0054 \pm 0.0012$ & $0.40 \pm 0.14$ & $0.40 \pm 0.27$ \\
\hline
\end{tabular}

$t$-test with Benjamini-Hochberg correction; * bold, significant difference with FDR $<0.05$. 
Table 4. Concentrations of cysteine and related metabolites in body fluids of rats on HCD and SD.

\begin{tabular}{|c|c|c|c|c|c|c|c|c|}
\hline & \multirow{2}{*}{\multicolumn{2}{|c|}{$\begin{array}{c}\text { Plasma } \\
\mu \mathrm{mol} / \mathrm{l} \\
\end{array}$}} & \multicolumn{2}{|c|}{ Urinary output } & \multicolumn{2}{|c|}{ Urine } & \multicolumn{2}{|c|}{ EF } \\
\hline & & & & & $\mu \mathrm{mol} / \mathrm{mmol}$ & creatinine & & \\
\hline & SD & HCD & SD & HCD & SD & HCD & SD & HCD \\
\hline Total cysteine & $187 \pm 12$ & $177 \pm 12$ & $44.7 \pm 14.7$ & $53.0 \pm 10.0$ & $11.1 \pm 3.0$ & $11.9 \pm 1.9$ & $0.2 \pm 0.0$ & $0.2 \pm 0.1$ \\
\hline \multicolumn{9}{|c|}{ Cysteine catabolism - decarboxylation pathway } \\
\hline Hypotaurine & $11.2 \pm 2.3$ & $10.5 \pm 2.8$ & $53.7 \pm 16.1$ & $123 \pm 26^{*}$ & $13.3 \pm 2.9$ & $27.7 \pm 6.0 *$ & $3.2 \pm 0.9$ & $8.5 \pm 3.4 *$ \\
\hline Taurine (Tau) & $262 \pm 59$ & $294 \pm 33$ & $1709 \pm 501$ & $5650 \pm 870 *$ & $425 \pm 90$ & $1265 \pm 153 *$ & $4.5 \pm 1.2$ & $13.2 \pm 1.9 *$ \\
\hline \multicolumn{9}{|c|}{ Cysteine catabolism - transamination pathway } \\
\hline Sulfite & $0.022 \pm 0.006$ & $0.017 \pm 0.003$ & $0.28 \pm 0.06$ & $0.27 \pm 0.09$ & $0.072 \pm 0.023$ & $0.060 \pm 0.019$ & $10.0 \pm 5.6$ & $10.4 \pm 4.6$ \\
\hline Sulfate & $1068 \pm 114$ & $994 \pm 86$ & $11275 \pm 2165$ & $18813 \pm 1138 *$ & $2842 \pm 427$ & $4231 \pm 292 *$ & $7.8 \pm 2.3$ & $13.6 \pm 0.8 *$ \\
\hline \multicolumn{9}{|c|}{ Decarboxylation/Transamination pathways ratio } \\
\hline Tau/Sulfate & $0.25 \pm 0.08$ & $0.30 \pm 0.06$ & $0.15 \pm 0.03$ & $0.30 \pm 0.04 *$ & $0.15 \pm 0.03$ & $0.30 \pm 0.04 *$ & NA & NA \\
\hline \multicolumn{9}{|c|}{ Cysteine catabolism - desulfhydration and related analytes } \\
\hline $\begin{array}{l}\text { Hydrogen } \\
\text { sulfide }\end{array}$ & $0.0031 \pm 0.0005$ & $0.0071 \pm 0.0047^{*}$ & NA & NA & NA & NA & NA & NA \\
\hline Thiosulfate & $1.14 \pm 0.30$ & $0.91 \pm 0.31$ & $2.45 \pm 0.41$ & $3.53 \pm 0.44 *$ & $0.62 \pm 0.11$ & $0.80 \pm 0.14 *$ & $1.5 \pm 0.5$ & $3.3 \pm 1.7^{*}$ \\
\hline Thiocyanate & $33.6 \pm 6.4$ & $43.6 \pm 8.2 *$ & $25.2 \pm 6.8$ & $41.3 \pm 12.1^{*}$ & $6.65 \pm 2.93$ & $9.31 \pm 2.94$ & $0.6 \pm 0.3$ & $0.7 \pm 0.2$ \\
\hline S-sulfocysteine & $1.80 \pm 0.14$ & $1.81 \pm 0.76$ & $2.54 \pm 0.56$ & $3.83 \pm 0.42 *$ & $0.63 \pm 0.06$ & $0.86 \pm 0.12 *$ & $1.0 \pm 0.2$ & $1.6 \pm 0.6^{*}$ \\
\hline Lanthionine & $0.034 \pm 0.005$ & $0.031 \pm 0.006$ & $0.068 \pm 0.015$ & $0.105 \pm 0.046$ & $0.017 \pm 0.003$ & $0.024 \pm 0.011$ & $1.4 \pm 0.4$ & $2.3 \pm 1.0$ \\
\hline \multicolumn{9}{|c|}{ Glutathione metabolism } \\
\hline Glutathione & $57.7 \pm 7.4$ & $43.6 \pm 13.8 *$ & $4.08 \pm 0.84$ & $5.13 \pm 1.19$ & $1.02 \pm 0.12$ & $1.14 \pm 0.22$ & $0.05 \pm 0.01$ & $0.1 \pm 0.1^{*}$ \\
\hline $\begin{array}{l}\gamma \text {-Glutamyl- } \\
\text { cysteine }\end{array}$ & $5.33 \pm 0.53$ & $4.62 \pm 0.78$ & NQ & NQ & NQ & NQ & NA & NA \\
\hline Cysteinylglycine & $1.20 \pm 0.15$ & $1.15 \pm 0.13$ & $25.6 \pm 4.8$ & $30.4 \pm 6.7$ & $6.47 \pm 1.14$ & $6.81 \pm 1.27$ & $15.4 \pm 4.2$ & $17.5 \pm 2.0$ \\
\hline \multicolumn{9}{|c|}{ Methionine cycle and related analytes } \\
\hline Methionine & $23.2 \pm 2.8$ & $19.0 \pm 3.1^{*}$ & $13.1 \pm 2.5$ & $14.5 \pm 2.7$ & $3.30 \pm 0.46$ & $3.22 \pm 0.42$ & $0.4 \pm 0.1$ & $0.5 \pm 0.1$ \\
\hline $\begin{array}{l}\text { Total } \\
\text { homocysteine }\end{array}$ & $2.71 \pm 0.14$ & $2.99 \pm 0.25^{*}$ & $1.78 \pm 0.99$ & $2.21 \pm 0.82$ & $0.44 \pm 0.21$ & $0.50 \pm 0.22$ & $0.5 \pm 0.3$ & $0.5 \pm 0.3$ \\
\hline Met/tHcy & $8.62 \pm 1.32$ & $6.36 \pm 1.14 *$ & $8.74 \pm 3.44$ & $7.18 \pm 2.28$ & $8.74 \pm 3.44$ & $7.18 \pm 2.28$ & & \\
\hline Choline & $10.1 \pm 0.8$ & $11.0 \pm 1.1$ & $98.3 \pm 33.6$ & $119 \pm 34$ & $25.5 \pm 10.6$ & $26.6 \pm 7.8$ & $7.0 \pm 2.8$ & $7.7 \pm 3.1$ \\
\hline Betaine & $207 \pm 16$ & $132 \pm 16^{*}$ & $627 \pm 156$ & $425 \pm 51^{*}$ & $156 \pm 22$ & $95 \pm 10^{*}$ & $2.1 \pm 0.3$ & $2.4 \pm 0.6$ \\
\hline Dimethylglycine & $10.9 \pm 0.8$ & $6.9 \pm 0.5^{*}$ & $257 \pm 70$ & $199 \pm 21$ & $63.8 \pm 9.6$ & $44.9 \pm 5.5^{*}$ & $16.2 \pm 1.8$ & $18.5 \pm 2.0$ \\
\hline Sarcosine & $1.73 \pm 0.22$ & $1.21 \pm 0.18^{*}$ & $29.1 \pm 8.9$ & $17.8 \pm 2.1^{*}$ & $7.25 \pm 1.57$ & $4.02 \pm 0.58 *$ & $11.7 \pm 2.1$ & $10.2 \pm 1.8$ \\
\hline
\end{tabular}

$t$-test with Benjamini-Hochberg correction; * bold, significant difference with FDR $<0.05$. 


\section{Glutathione related metabolites}

As Cys is a substrate for GSH synthesis, we evaluated the impact of HCD on the concentrations of GSH and related metabolites. Plasma GSH was decreased to $\approx 0.8$-fold and EF GSH was elevated to $\approx 2$-fold while there were no significant changes in concentrations of intermediates in GSH synthesis (gamma-glutamylcysteine) and degradation product (cysteinylglycine).

\section{Metabolites of the methionine cycle}

We observed significantly decreased levels of Met (to $\approx 0.8$-fold) and slightly increased levels of total homocysteine (to $\approx 1.1$-fold) in plasma of HCD rats. The decrease of Met/total homocysteine ratio to $\approx 0.7$-fold may indicate an impaired remethylation of homocysteine to Met. Interestingly, the methyl group donor in one of the two remethylation reactions, betaine, was decreased to $\approx 0.5$-0.8-fold in all analyzed tissues except muscle and in body fluids of rats on HCD. In addition, the betaine demethylation metabolites - dimethylglycine and sarcosine - were also decreased to $\approx 0.5$-0.8-fold in liver, kidney, plasma and urine of HCD fed rats. On the other hand, the precursor of betaine synthesis - choline - was significantly elevated (to $\approx 2$-fold) only in muscles of rats on HCD.

\section{Effects of HCD on hepatic gene expression profiles}

Using RNAseq we observed significantly deregulated expression levels of 22 transcripts (Table S3). Data were subsequently evaluated by gene enrichment analysis using KEGG pathways map. SHR-CRP rats fed a HCD had significantly increased hepatic expression of circadian rhythms pathway genes Per1, Per3 and Nrld1 and reduced expression of Cxcl10 and Rnf125 genes in the RIG-I-like receptor signaling pathway suggesting reduced inflammation. In addition, the RNAseq analysis revealed suggestive deregulated expression of Csad (cysteinesulfinic acid decarboxylase), Slc6a6 (solute carrier family 6 member 6 , also known as taurine transporter) and Mthfr (methylenetetrahydrofolate reductase) genes. However, qPCR testing of selected genes involved in sulfur metabolism confirmed only significantly downregulated expression of the Slc6a6 gene after HCD while deregulation of the Csad and Mthfr genes did not reach statistical significance (Fig. 2).

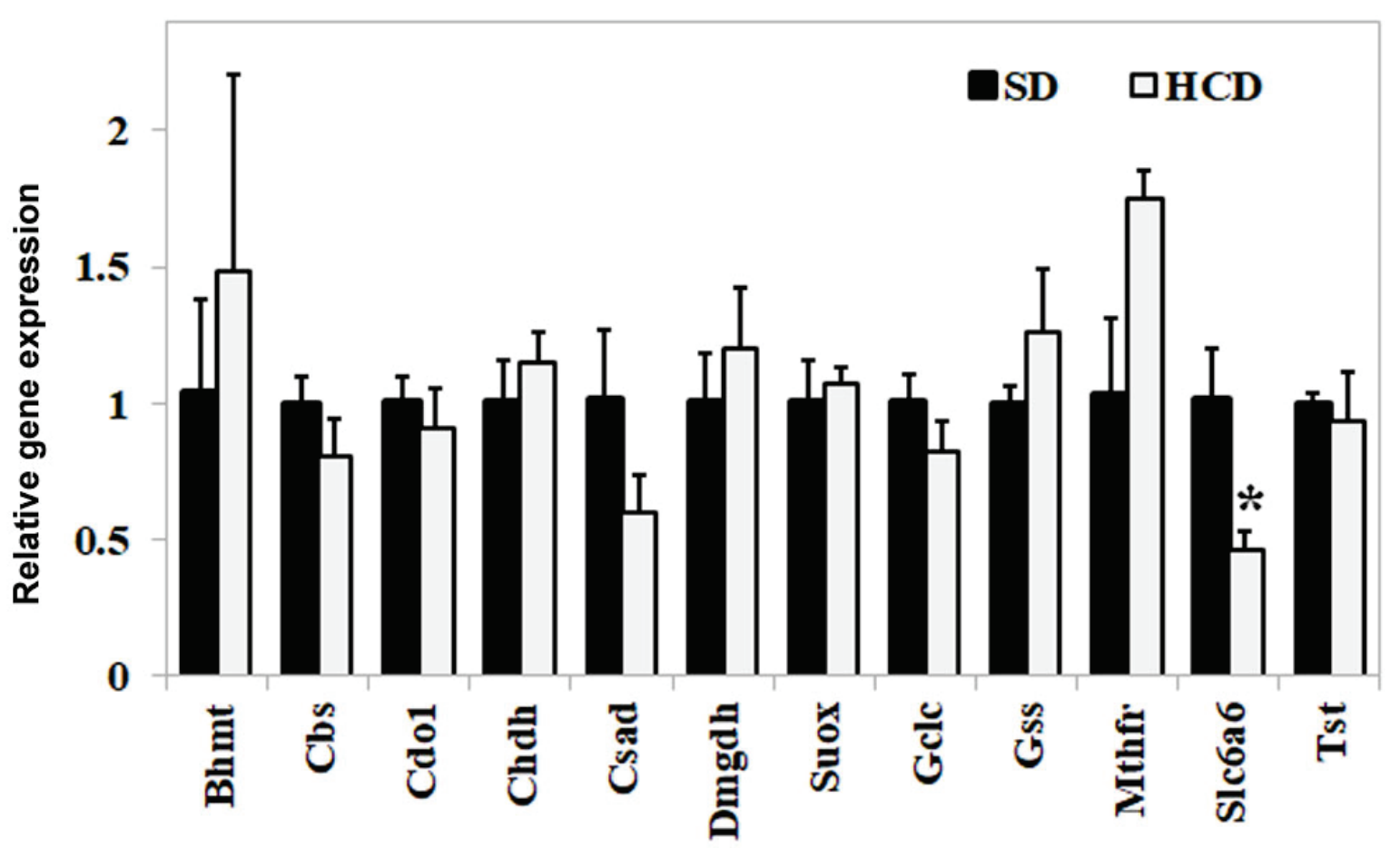

Fig. 2. Hepatic expression of selected genes in sulfur metabolic pathways. The open bars indicate relative expression of genes analyzed by qPCR in animals on HCD. Expression of genes on SD was set to 1.0, Differences between animals on HCD and SD were evaluated by $t$-test with Benjamini-Hochberg correction, *indicates significant difference; Abbreviations: Bhmt, betaine:homocysteine methyltransferase; $C b s$, cystathionine beta-synthase; Cdo1, cysteine dioxygenase; Chdh, choline dehydrogenase; Csad, cysteine sulfinic acid decarboxylase; Dmgdh, dimethylglycine dehydrogenase; Suox, sulfite oxidase; Gc/c, glutamate-cysteine ligase, catalytic subunit; GsS, glutathione synthase; Mthfr, methylenetetrahydrofolate reductase; S/c6a6, solute carrier family 6 member 6 ; Tst, thiosulfate transferase. 


\section{Discussion}

Previous studies consistently showed that elevated plasma tCys is associated with several components of metabolic syndrome in humans (Elshorbagy et al. 2012c, Elshorbagy et al. 2012b, El-Khairy et al. 1999, Elshorbagy et al. 2008). Moreover, reduced sulfur amino acid intake had beneficial effect on circulating markers of metabolic syndrome and gene expression in adipose tissues (Olsen et al. 2020). In the present study we used an established rodent model of metabolic syndrome and inflammation, the SHR-CRP rats, to explore the hypothesis that increased Cys intake induces obesity and increases insulin resistance. In contrary, our study showed that feeding the SHR-CRP animals a diet enriched with Cys did not increase obesity while it ameliorated insulin resistance and decreased oxidative stress. Although some previous studies reported impairment of metabolic syndrome on HCD (Elshorbagy et al. 2012a), results of our study are similar to previous reports of beneficial effect of Cys supplementation on markers of oxidative stress and components of metabolic syndrome (Jain et al. 2009, Blouet et al. 2007). However, since we did not measure food intake it may be possible that the lack of effect of the HCD on body weight/fat mass could be due to unrecognized effects of the diet on caloric intake. Higher Cys intake did not change concentrations of tCys in tissues and body fluids, and resulted in elevation and decrease of Tau and betaine, respectively, and changes in expression of circadian rhythms and inflammation related genes.

We estimated that the daily intake of sulfur amino acids in the HCD and SD fed rats was $\approx 2.3$ mmoles and $\approx 1.3$ mmoles, respectively. Despite $\sim 70 \%$ higher sulfur amino acid load in HCD fed rats we did not observe any increase of tCys in tissue, plasma or urine. Previous studies of rodents on HCD also demonstrated such tight regulation of Cys homeostasis, which is likely mediated by abundance and/or activity of CDO, CSAD and glutamate-cysteine ligase (GCL) (Stipanuk 2020). In our study, RNAseq and qPCR analyses did not reveal any significant changes in Cdol gene expression in liver from HCD-fed rats despite clearly increased urinary losses of the end products of the CDO-mediated catabolic pathways. This agrees with previous studies showing that changes in gene expression probably play a minor role in regulating CDO activity in Cys overload. CDO is activated mainly posttranscriptionally via formation of a cysteinyl-tyrosine crosslink in the active site of CDO enzyme and by inhibited degradation via the ubiquitin-proteasome system (Dominy et al. 2006, Stipanuk et al. 2009). In contrast to previous studies in rats on HCD (Vidal et al. 2014) we did not observe any significant changes in GSH and GSH-related metabolites or differences in hepatic expression of Gclc.

Cys is catabolized via two CDO-dependent pathways (decarboxylation and transamination) and several reactions in the desulfhydration pathway. Data from our study allow us to roughly estimate the diversion of Cys among these routes. Although we were unable to determine the unstable intermediates cysteinesulfinate and sulfinylpyruvate in the decarboxylation and transamination pathways, these CDO-dependent pathways appear to be the major routes for removing excess Cys. The daily urinary output of Tau increased by $\approx 0.1$ mmoles/day while sulfate excretion rose by $\approx 0.2$ mmoles/day, suggesting that partitioning of cysteinesulfinate between the decarboxylation and transamination pathways favors transamination with a caveat that an unknown proportion of sulfate may originate from oxidation of sulfite that is generated via desulfhydration of Cys. Partitioning of cysteinesulfinate between decarboxylation and transamination is modulated by CSAD. Indeed, we observed a decreased expression (albeit not significant with the $\mathrm{p}=0.096$ ) of Csad in the livers of HCD rats which is similar to previous reports (Bella et al. 1999, Jurkowska et al. 2016). The desulfhydration reactions producing $\mathrm{H}_{2} \mathrm{~S}$ appear to play a lesser role in maintaining Cys homeostasis and become more important only in CDO deficiency or Cys starvation when CDO levels are very low (Stipanuk and Ueki 2011, Stipanuk 2020). In our study, $\mathrm{H}_{2} \mathrm{~S}$ concentration was not increased in tissues but it was doubled in plasma of HCD-fed rats; however, the latter data should be interpreted with caution due to possible preanalytical intricacies of collecting blood after decapitation. Lanthionine, a marker of Cys desulfhydration, was not significantly elevated in body fluids and tissues except muscle, further supporting a lower flux via the desulfhydration pathway. However, higher flux of Cys via both the transamination and desulfhydration pathways that generate sulfite is also indirectly indicated by an increased urinary excretion of S-sulfocysteine, thiosulfate and thiocyanate.

Extensive metabolite profiling revealed also unexpected changes in the remethylation pathway of homocysteine. We observed decreased concentration of 
the methyl group donor betaine and its demethylated derivatives - dimethylglycine and sarcosine - in tissues and body fluids. The origin of these changes remains obscure as the hepatic expression of genes involved in betaine synthesis and metabolism - choline dehydrogenase, betaine aldehyde dehydrogenase, dimethylglycine dehydrogenase, sarcosine dehydrogenase - did not differ between $\mathrm{HCD}$ and $\mathrm{SD}$ rats except for increased expression of the Bhmt gene in HCD, however, the difference was not statistically significant. Lower concentration of betaine may in turn decrease the supply of methyl groups for the BHMT-dependent conversion of homocysteine to Met as indicated by the decreased Met/total homocysteine ratio in liver.

The beneficial effects of HCD on metabolic syndrome components may be in part mediated by increased concentrations of Tau (Imae et al. 2014). Previous reports showed that Tau supplementation decreased weight gain and adiposity in mice (Tsuboyama-Kasaoka et al. 2006), reduced insulin resistance and blood glucose levels, and decreased serum levels of triglycerides and leptin in a model of type 2 diabetes rats (Kim et al. 2012) and inhibited insulin stimulated $\mathrm{H}_{2} \mathrm{O}_{2}$ release and activation of lipolysis in adipocytes (Pina-Zentella et al. 2012). In addition, elevated Tau concentrations were previously shown to downregulate expression the Slc6a6 gene that encodes the taurine transporter (TauT) with subsequently decreased differentiation of adipose-derived stem cells to adipocytes via a beta-catenin related mechanism (Hou et al. 2019). The important role of TauT in adipogenesis was shown in the Slc6a6 knockout mice that exhibited lower body weight and abdominal fat mass (Ito et al. 2015). In our study, decreased hepatic expression of Slc6a6 gene in SHR-CRP animals on HCD was not accompanied by decreased adiposity or liver triglyceride concentration, however, triglycerides content was significantly reduced in the myocardium.

Other mechanisms may be mediated by deregulated expression of genes in the circadian rhythms and RIG-I-like receptor signalling pathways, respectively. Per1 (period circadian regulator 1), Per3 (period circadian regulator 3) and Nrldl (nuclear receptor subfamily 1 , group D, member 1) genes play important role in regulating circadian rhythms and metabolism. For instance, knock-out of $\mathrm{Nr} 1 \mathrm{dl}$ gene in mice was associated with hepatic steatosis ( $\mathrm{Na}$ et al. 2016). In addition, Nrldl ablation in mice suppressed glycolysis and fatty acid oxidation in white adipose tissue (WAT), whereas partial
Nr1d1 loss in heterozygotes, curiously stimulated these processes. Thus, Nrldl dose-dependently regulates glucose metabolism and fatty acid oxidation in WAT and muscle (Welch et al. 2020). Both Cxcl10 (C-X-C motif chemokine ligand 10) and Rnf125 (ring finger protein 125) genes play important role in innate immunity and are downregulated in rats fed HCD which suggests reduced inflammation.

\section{Conclusions}

In conclusion, this study showed various effects of HCD on the metabolic and molecular outcomes in SHR-CRP rats. Some of these effects (e.g. the lack of obesogenic effects and amelioration of insulin resistance in rats fed HCD) seem to contradict the hypothesis that Cys promotes obesity and metabolic syndrome in humans. It is possible that these positive effects of HCD on selected metabolic syndrome parameters result from elevated Tau levels, which may protect against obesity and insulin resistance. These results in a rodent model, however, are not necessarily in conflict with the established association of tCys with components of metabolic syndrome in humans. It is possible that increased tCys levels detected in obese individuals may result not only from an increased Cys intake but also from impaired Cys catabolism. Defect in CDO activity, which may lead to higher Cys levels and reduced levels of the metabolic syndrome ameliorating compound Tau may be an example of another mechanism that increases tCys in humans with metabolic syndrome. Further studies are needed to evaluate these hypotheses.

\section{Conflict of Interest}

There is no conflict of interest.

\section{Acknowledgements}

This work was supported by the grant from the Czech Health Research Council Nr. 16-30384A and by the Ministry of Health of the Czech Republic under the conceptual development of research organizations programs (Institute for Clinical and Experimental Medicine - IKEM, IN 00023001; General University Hospital in Prague- RVO VFN 64165). This work was also supported by ELIXIR CZ research infrastructure project (MEYS Grant No: LM2018131) including access to computing and storage facilities and by institutional support of the Institute of Molecular Genetics CAS RVO: 68378050. P. N. acknowledges financial support 
from the National Laboratories Excellence program (under the National Tumorbiology Laboratory project).
The authors would like to thank Olena Oliyarnyk for oxidative stress analysis.

\section{References}

BELLA DL, HAHN C, STIPANUK MH: Effects of nonsulfur and sulfur amino acids on the regulation of hepatic enzymes of cysteine metabolism. Am J Physiol 277: E144-E153, 1999. https://doi.org/10.1152/ajpendo.1999.277.1.E144

BLOUET C, MARIOTTI F, AZZOUT-MARNICHE D, MATHE V, MIKOGAMI T, TOME D, HUNEAU JF: Dietary cysteine alleviates sucrose-induced oxidative stress and insulin resistance. Free Radic Biol Med 42: 1089-1097, 2007. https://doi.org/10.1016/j.freeradbiomed.2007.01.006

BROSNAN JT, BROSNAN ME: The sulfur-containing amino acids: an overview. J Nutr 136: 1636S-1640S, 2006. https://doi.org/10.1093/jn/136.6.1636S

DITROI T, NAGY A, MARTINELLI D, ROSTA A, KOŽICH V, NAGY P: Comprehensive analysis of how experimental parameters affect $\mathrm{H} 2 \mathrm{~S}$ measurements by the monobromobimane method. Free Radic Biol Med 136: 146-158, 2019. https://doi.org/10.1016/j.freeradbiomed.2019.04.006

DOMINY JE JR, HIRSCHBERGER LL, COLOSO RM, STIPANUK MH: In vivo regulation of cysteine dioxygenase via the ubiquitin-26S proteasome system. Adv Exp Med Biol 583: 37-47, 2006. https://doi.org/10.1007/978-0387-33504-9_4

EL-KHAIRY L, UELAND PM, NYGARD O, REFSUM H, VOLLSET SE: Lifestyle and cardiovascular disease risk factors as determinants of total cysteine in plasma: The Hordaland homocysteine study. Am J Clin Nutr 70: 1016-1024, 1999. https://doi.org/10.1093/ajcn/70.6.1016

ELSHORBAGY AK, CHURCH C, VALDIVIA-GARCIA M, SMITH AD, REFSUM H, COX R: Dietary cystine level affects metabolic rate and glycaemic control in adult mice. $J$ Nutr Biochem 23: 332-340, 2012a. https://doi.org/10.1016/j.jnutbio.2010.12.009

ELSHORBAGY AK, KOŽICH V, SMITH AD, REFSUM H: Cysteine and obesity: consistency of the evidence across epidemiologic, animal and cellular studies. Curr Opin Clin Nutr Metab Care 15: 49-57, 2012b. https://doi.org/10.1097/MCO.0b013e32834d199f

ELSHORBAGY AK, NURK E, GJESDAL CG, TELL GS, UELAND PM, NYGARD O, TVERDAL A, VOLLSET SE, REFSUM H: Homocysteine, cysteine, and body composition in the Hordaland Homocysteine Study: does cysteine link amino acid and lipid metabolism? Am J Clin Nutr 88: 738-746, 2008. https://doi.org/10.1093/ajen/88.3.738

ELSHORBAGY AK, SMITH AD, KOŽICH V, REFSUM H: Cysteine and obesity. Obesity (Silver Spring) 20: 473-481, 2012c. https://doi.org/10.1038/oby.2011.93

ELSHORBAGY AK, VALDIVIA-GARCIA M, REFSUM H, BUTTE N: The association of cysteine with obesity, inflammatory cytokines and insulin resistance in Hispanic children and adolescents. PLoS One 7: e44166, 2012d. https://doi.org/10.1371/journal.pone.0044166

HOU X, WANG Z, DING F, HE Y, WANG P, LIU X, XU F, WANG J, YANG Y: Taurine transporter regulates adipogenic differentiation of human adipose-derived stem cells through affecting Wnt/beta-catenin signaling pathway. Int J Biol Sci 15: 1104-1112, 2019. https://doi.org/10.7150/ijbs.31794

IMAE M, ASANO T, MURAKAMI S: Potential role of taurine in the prevention of diabetes and metabolic syndrome. Amino Acids 46: 81-88, 2014. https://doi.org/10.1007/s00726-012-1434-4

ITO T, YOSHIKAWA N, ITO H, SCHAFFER SW: Impact of taurine depletion on glucose control and insulin secretion in mice. J Pharmacol Sci 129: 59-64, 2015. https://doi.org/10.1016/j.jphs.2015.08.007

JAIN SK, VELUSAMY T, CROAD JL, RAINS JL, BULL R: L-cysteine supplementation lowers blood glucose, glycated hemoglobin, CRP, MCP-1, and oxidative stress and inhibits NF-kappaB activation in the livers of Zucker diabetic rats. Free Radic Biol Med 46: 1633-1638, 2009. https://doi.org/10.1016/j.freeradbiomed.2009.03.014

JURKOWSKA H, NIEWIADOMSKI J, HIRSCHBERGER LL, ROMAN HB, MAZOR KM, LIU X, LOCASALE JW, PARK E, STIPANUK MH: Downregulation of hepatic betaine:homocysteine methyltransferase (BHMT) expression in taurine-deficient mice is reversed by taurine supplementation in vivo. Amino Acids 48: 665-676, 2016. https://doi.org/10.1007/s00726-015-2108-9 
KIM KS, OH DH, KIM JY, LEE BG, YOU JS, CHANG KJ, CHUNG HJ, YOO MC, YANG HI, KANG JH, HWANG YC, AHN KJ, CHUNG HY, JEONG IK: Taurine ameliorates hyperglycemia and dyslipidemia by reducing insulin resistance and leptin level in Otsuka Long-Evans Tokushima fatty (OLETF) rats with long-term diabetes. Exp Mol Med 44: 665-673, 2012. https://doi.org/10.3858/emm.2012.44.11.075

KOŽICH V, DITROI T, SOKOLOVÁ J, KŘIŽKOVÁ M, KRIJT J, JEŠINA P, NAGY P: Metabolism of sulfur compounds in homocystinurias. Br J Pharmacol 176: 594-606, 2019. https://doi.org/10.1111/bph.14523

KRIJT J, VACKOVÁ M, KOŽICH V: Measurement of homocysteine and other aminothiols in plasma: advantages of using tris(2-carboxyethyl)phosphine as reductant compared with tri-n-butylphosphine. Clin Chem 47: 1821-1828, 2001. https://doi.org/10.1093/clinchem/47.10.1821

LUNOVA M, KUBOVČIAK J, SMOLKOVÁ B, UZHYTCHAK M, MICHALOVÁ| K, DEJNEKA A, STRNAD P, LUNOV O, JIRSA M: Expression of interferons lambda 3 and 4 induces identical response in human liver cell lines depending exclusively on canonical signaling. Int J Mol Sci 22, 2021. https://doi.org/10.3390/ijms22052560

MALINSKÁ H, HÜTTL M, OLIYARNYK O, BRATOVÁ M, KAZDOVÁ L: Conjugated linoleic acid reduces visceral and ectopic lipid accumulation and insulin resistance in chronic severe hypertriacylglycerolemia. Nutrition 31: 1045-1051, 2015. https://doi.org/10.1016/j.nut.2015.03.011

NA H, LEE H, LEE MH, LIM HJ, KIM HJ, JEON Y, KANG HL, LEE MO: Deletion of exons 3 and 4 in the mouse Nr1d1 gene worsens high-fat diet-induced hepatic steatosis. Life Sci 166: 13-19, 2016. https://doi.org/10.1016/j.1fs.2016.10.003

NIEWIADOMSKI J, ZHOU JQ, ROMAN HB, LIU X, HIRSCHBERGER LL, LOCASALE JW, STIPANUK MH: Effects of a block in cysteine catabolism on energy balance and fat metabolism in mice. Ann N Y Acad Sci 1363: 99-115, 2016. https://doi.org/10.1111/nyas.13021

OLSEN T, OVREBO B, HAJ-YASEIN N, LEE S, SVENDSEN K, HJORTH M, BASTANI NE, NORHEIM F, DREVON CA, REFSUM H, VINKNES KJ: Effects of dietary methionine and cysteine restriction on plasma biomarkers, serum fibroblast growth factor 21, and adipose tissue gene expression in women with overweight or obesity: a double-blind randomized controlled pilot study. J Transl Med 18: 122, 2020. https://doi.org/10.1186/s12967-020$\underline{02288-\mathrm{x}}$

OLSEN T, OVREBO B, TURNER C, BASTANI NE, REFSUM H, VINKNES KJ: Combining dietary sulfur amino acid restriction with polyunsaturated fatty acid intake in humans: a randomized controlled pilot trial. Nutrients 10, 2018. https://doi.org/10.3390/nu10121822

PINA-ZENTELLA G, DE LA ROSA-CUEVAS G, VAZQUEZ-MEZA H, PINA E, DE PINA MZ: Taurine in adipocytes prevents insulin-mediated H2O2 generation and activates Pka and lipolysis. Amino Acids 42: 1927-1935, 2012. https://doi.org/10.1007/s00726-011-0919-x

PRAVENEC M, KAJIYA T, ZÍDEK V, LANDA V, MLEJNEK P, ŠIMÁKOVÁ M, ŠILHAVÝ J, MALINSKÁ H, OLIYARNYK O, KAZDOVÁ L, FAN J, WANG J, KURTZ TW: Effects of human C-reactive protein on pathogenesis of features of the metabolic syndrome. Hypertension 57: 731-737, 2011. https://doi.org/10.1161/HYPERTENSIONAHA.110.164350

STIPANUK MH: Metabolism of sulfur-containing amino acids: how the body copes with excess methionine, cysteine, and sulfide. J Nutr 150: 2494S-2505S, 2020. https://doi.org/10.1093/jn/nxaa094

STIPANUK MH, DOMINY JE JR, LEE JI, COLOSO RM: Mammalian cysteine metabolism: new insights into regulation of cysteine metabolism. J Nutr 136: 1652S-1659S, 2006. https://doi.org/10.1093/jn/136.6.1652S

STIPANUK MH, UEKI I: Dealing with methionine/homocysteine sulfur: cysteine metabolism to taurine and inorganic sulfur. J Inherit Metab Dis 34: 17-32, 2011. https://doi.org/10.1007/s10545-009-9006-9

STIPANUK MH, UEKI I, DOMINY JE JR, SIMMONS CR, HIRSCHBERGER LL: Cysteine dioxygenase: a robust system for regulation of cellular cysteine levels. Amino Acids 37: 55-63, 2009. https://doi.org/10.1007/s00726$\underline{008-0202-\mathrm{y}}$

TSUBOYAMA-KASAOKA N, SHOZAWA C, SANO K, KAMEI Y, KASAOKA S, HOSOKAWA Y, EZAKI O: Taurine (2-aminoethanesulfonic acid) deficiency creates a vicious circle promoting obesity. Endocrinology 147: 3276-3284, 2006. https://doi.org/10.1210/en.2005-1007 
VIDAL K, BREUILLE D, SERRANT P, DENIS P, GLOMOT F, BECHEREAU F, PAPET I: Long-term cysteine fortification impacts cysteine/glutathione homeostasis and food intake in ageing rats. Eur J Nutr 53: 963-971, 2014. https://doi.org/10.1007/s00394-013-0600-0

WELCH RD, BILLON C, KAMERIC A, BURRIS TP, FLAVENY CA: Rev-erb $\alpha$ heterozygosity produces a dosedependent phenotypic advantage in mice. PLoS One 15: e0227720, 2020. https://doi.org/10.1371/journal.pone.0227720

YE J, COULOURIS G, ZARETSKAYA I, CUTCUTACHE I, ROZEN S, MADDEN TL: Primer-BLAST: a tool to design target-specific primers for polymerase chain reaction. BMC Bioinformatics 13: 134, 2012. https://doi.org/10.1186/1471-2105-13-134 
Supplementary Table 1. Primers for qPCR reactions.

\begin{tabular}{lc}
\hline Bhmt_e7F & GACATGCACACCAAACCCTG \\
Bhmt_e8R & AAGGATTGTACGGTCTGCCC \\
Cbs_e13F & CCTCCGGGAGAAGGGTTTTG \\
Cbs_e14R & CATGTTCCCGAGAGTCACCA \\
Cdo1_e4F & GCCTTTGACCAACGAACAGG \\
Cdo1_e5R & CTTTGAAAGGCTTGGCAGGTC \\
Chdh_e4F & CTGCTCATGCTCTCTGGTGT \\
Chdh_e5R & GTCCTGCAGGTTCTGACCAA \\
Csad_e5F & TGGGGATGGGGTCTTCTGT \\
Csad_e7R & CTTGGTGATGGAGTAGTGGCA \\
Dmgdh_e9F & GGAACAGCCACACTGGTTCTA \\
Dmgdh_e10R & ACTTGCCAAACGGAGACAGG \\
Suox_e1Fb & CAATGCTGCCTCGGCTATACA \\
Suox_e2Rb & CTCAAGGGGGTTGACTTGGC \\
Gclc_e15F & GTGGACACCCGATGCAGTAT \\
Gclc_e16R & TCATCCACCTGGCAACAGTC \\
Gss_e8F & AGACCAAAACCGAAGGCTGT \\
Gss_e9R & GGCATGTAGCCATCTCGGAA \\
Mthfr_e10F & GAGAAACCGTGGAGGCTCTT \\
Mthfr_e11R & CAGCTCAGGGGCATTAGTGAT \\
Slc6a6_e11F & AGGAAGGGTTATCGTCGGGA \\
Slc6a6_e12R & GCGACCCACAAAAGGCATAC \\
Tst_e1F & CTCAAGACCTATGAGCAGGTCC \\
Tst_e2R & ACGTTGACAGAGCCACGGAT \\
Ppia_c59F & TGTTCTTCGACATCACGGCT \\
Ppia_c178R & ATCCTTTCTCCCCAGTGCTC \\
\hline
\end{tabular}


Supplementary Table 2. Fold changes in metabolite concentrations in animals on HCD versus SD.

\section{LIVER KIDNEY BRAIN MUSCLE PLASMA $\begin{gathered}\text { Urinary } \\ \text { output }\end{gathered}$ URINE EF}

\begin{tabular}{|c|c|c|c|c|c|c|c|c|}
\hline \multicolumn{9}{|c|}{ Analyte fold difference - HCD versus SD } \\
\hline Total cysteine & 0.92 & 0.97 & 0.90 & 0.62 & 0.95 & 1.19 & 1.07 & 1.00 \\
\hline \multicolumn{9}{|c|}{ Methionine cycle related analytes } \\
\hline Methionine & 0.91 & 0.99 & 0.94 & 1.10 & 0.82* & 1.11 & 0.98 & 1.25 \\
\hline Total homocysteine & 1.00 & 0.96 & 0.84 & 1.17 & $1.10 *$ & 1.24 & 1.14 & 1.00 \\
\hline Met/tHcy & 0.91 & 1.04 & 1.31 & 1.42 & $0.74^{*}$ & 0.82 & 0.82 & - \\
\hline Choline & 1.08 & 1.00 & 0.98 & $1.98^{*}$ & 1.09 & 1.21 & 1.04 & 1.10 \\
\hline Betaine & $0.49 *$ & $0.72 *$ & $0.77 *$ & 0.83 & $0.64^{*}$ & $0.68 *$ & $0.61 *$ & 1.14 \\
\hline Dimethylglycine & $0.51 *$ & $0.63^{*}$ & 0.55 & 0.93 & $0.63^{*}$ & 0.77 & $0.70^{*}$ & 1.14 \\
\hline Sarcosine & 0.83 & $0.77^{*}$ & 0.79 & 1.00 & $0.70^{*}$ & $0.61 *$ & $0.55^{*}$ & 0.87 \\
\hline \multicolumn{9}{|c|}{ Cysteine catabolism - decarboxylation pathway analytes } \\
\hline Hypotaurine & 1.03 & 1.10 & $1.13^{*}$ & 1.45 & 0.94 & $2.29 *$ & $2.08 *$ & $2.66^{*}$ \\
\hline Taurine & $4.52 *$ & $1.23 *$ & $0.82 *$ & $1.50 *$ & 1.12 & $3.31 *$ & $2.98 *$ & $2.93^{*}$ \\
\hline \multicolumn{9}{|c|}{ Cysteine catabolism - transamination pathway analytes } \\
\hline Sulfite & 1.06 & 1.06 & 1.00 & 1.23 & 0.77 & 0.96 & 0.83 & 1.04 \\
\hline Sulfate & NA & NA & NA & NA & 0.93 & $1.67 *$ & $1.49 *$ & $1.74^{*}$ \\
\hline \multicolumn{9}{|c|}{ Decarboxylation/Transamination pathways ratio } \\
\hline Tau/sulfate & & & & & 1.20 & $2.00 *$ & $2.00 *$ & \\
\hline \multicolumn{9}{|c|}{ Cysteine catabolism - desulfhydration and related analytes } \\
\hline Hydrogen sulfide & 1.15 & 1.17 & NA & NA & $2.29 *$ & NA & NA & NA \\
\hline Thiosulfate & 0.92 & 0.94 & 0.81 & 1.00 & 0.80 & $1.44 *$ & $1.29 *$ & $2.20 *$ \\
\hline Thiocyanate & 0.83 & 0.93 & $0.84 *$ & 1.28 & $1.30 *$ & $1.64 *$ & 1.40 & 1.17 \\
\hline S-sulfocysteine & ND & ND & ND & ND & 1.01 & $1.51 *$ & $1.37 *$ & $1.60 *$ \\
\hline Lanthionine & ND & 0.95 & 1.09 & $1.60 *$ & 0.91 & 1.54 & 1.41 & 1.64 \\
\hline \multicolumn{9}{|c|}{ Glutathion metabolism analytes } \\
\hline Glutathione & 0.99 & 1.08 & 0.85 & 1.39 & $0.76^{*}$ & 1.26 & 1.12 & $2.00 *$ \\
\hline$\gamma$-glutamylcysteine & 1.24 & 1.07 & 1.06 & 0.97 & 0.87 & ND & ND & NA \\
\hline Cysteinylglycine & 0.97 & 1.04 & 1.00 & 0.67 & 0.96 & 1.19 & 1.05 & 1.14 \\
\hline
\end{tabular}

NA, not analysed, ND, not determined, below the LLQ, The differences were calculated from the corresponding means in the rat group on $\mathrm{HCD}$ and SD; * bold, significant difference. 
Supplementary Table 3. Significantly deregulated genes in Liver from rats on HCD or SD.

\begin{tabular}{|c|c|c|c|c|}
\hline Gene & Name & $\begin{array}{c}\text { Fold } \\
\text { change }\end{array}$ & P value & $\begin{array}{l}\text { Corrected } \\
\text { P value }\end{array}$ \\
\hline Dbp & D-box binding PAR bZIP transcription factor & 2.89 & $1.47 e-39$ & $1.53 e-35$ \\
\hline Mfsd2a & major facilitator superfamily domain containing 2A & 1.63 & $3.51 \mathrm{e}-34$ & $1.82 \mathrm{e}-30$ \\
\hline Il6r & interleukin 6 receptor & 1.09 & 4.15e-22 & $1.44 \mathrm{e}-18$ \\
\hline Por & cytochrome p450 oxidoreductase & 1.02 & $1.79 \mathrm{e}-18$ & 4.32e-15 \\
\hline Usp2 & ubiquitin specific peptidase 2 & 1.55 & $2.47 e-18$ & $4.32 \mathrm{e}-15$ \\
\hline Per1 & period circadian regulator 1 & 1.50 & $2.49 \mathrm{e}-18$ & $4.32 \mathrm{e}-15$ \\
\hline Nr1d1 & nuclear receptor subfamily 1 , group $\mathrm{D}$, member 1 & 1.01 & $1.46 \mathrm{e}-17$ & $2.17 \mathrm{e}-14$ \\
\hline Herpud1 & $\begin{array}{l}\text { homocysteine inducible ER protein with ubiquitin like } \\
\qquad \text { domain } 1\end{array}$ & 1.11 & $3.08 \mathrm{e}-16$ & 3.56e-13 \\
\hline Rnf125 & ring finger protein 125 & -1.18 & $6.00 \mathrm{e}-14$ & $6.23 e-11$ \\
\hline Per3 & period circadian regulator 3 & 2.20 & $2.34 \mathrm{e}-12$ & 2.03e-09 \\
\hline Osgin1 & oxidative stress induced growth inhibitor 1 & -1.18 & $3.34 \mathrm{e}-12$ & 2.67e-09 \\
\hline Creld2 & cysteine-rich with EGF-like domains 2 & 1.05 & $5.15 \mathrm{e}-12$ & 3.82e-09 \\
\hline RGD1562310 & RIKEN cDNA 2410131K14 gene & 1.10 & 3.38e-11 & $2.19 \mathrm{e}-08$ \\
\hline Angptl4 & angiopoietin-like 4 & -1.00 & $1.67 \mathrm{e}-10$ & 8.91e-08 \\
\hline Cxcl10 & C-X-C motif chemokine ligand 10 & -1.12 & $8.41 \mathrm{e}-10$ & $4.16 \mathrm{e}-07$ \\
\hline Ciart & circadian associated repressor of transcription & 2.46 & $1.01 \mathrm{e}-09$ & $4.75 \mathrm{e}-07$ \\
\hline Srms & $\begin{array}{l}\text { src-related kinase lacking C-terminal regulatory tyrosine } \\
\text { and N-terminal myristylation sites }\end{array}$ & -1.25 & $9.98 \mathrm{e}-09$ & 3.58e-06 \\
\hline Cib2 & calcium and integrin binding family member 2 & -1.17 & $1.27 \mathrm{e}-08$ & 3.96e-06 \\
\hline Zfp354a & zinc finger protein 354A & 1.64 & $1.29 \mathrm{e}-08$ & $3.96 \mathrm{e}-06$ \\
\hline Nim1k & NIM1 serine/threonine protein kinase & -1.30 & $1.01 \mathrm{e}-07$ & $2.47 \mathrm{e}-05$ \\
\hline Mybl1 & MYB proto-oncogene like 1 & -1.01 & $1.02 \mathrm{e}-07$ & $2.47 \mathrm{e}-05$ \\
\hline Gtse1 & G-2 and S-phase expressed 1 & 1.16 & $1.52 \mathrm{e}-07$ & 3.50e-05 \\
\hline
\end{tabular}

